\title{
Proceedings Report of the International Invitation Workshop on Developmental Assurance
}

June $16-17,1994$

Turf Valley Country Club

Ellicott City, MD

\section{P. Toth}

U.S. DEPARTMENT OF COMMERCE

Technology Administration

National Institute of Standards

and Technology

Gaithersburg, MD 20899

$Q C$ 



\section{NISTIR 5590}

\section{Proceedings Report of the International Invitation Workshop on Developmental Assurance}

June $16-17,1994$

Turf Valley Country Club

Ellicott City, MD

\section{P. Toth}

U.S. DEPARTMENT OF COMMERCE Technology Administration

National Institute of Standards and Technology

Gaithersburg, MD 20899

January 1995

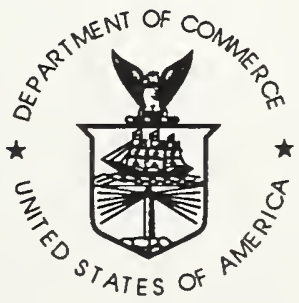

U.S. DEPARTMENT OF COMMERCE Ronald H. Brown, Secretary

TECHNOLOGY ADMINISTRATION

Mary L. Good, Under Secretary for Technology

NATIONAL INSTITUTE OF STANDARDS

AND TECHNOLOGY

Arati Prabhakar, Director 



\author{
Proceedings Report \\ of the \\ International Invitational Workshop \\ on \\ Developmental Assurance \\ June 16-17, 1994 \\ Turf Valley Country Club \\ Ellicott City, Maryland
}


Table of Contents

EXECUTIVE SUMMARY 4

INTRODUCTION 6

FORMULATION OF THE DEVELOPMENTAL ASSURANCE CONCEPT 6

CALL FOR PAPERS

FORMAT OF THE WORKSHOP

CONCLUSIONS \& RECOMMENDATIONS

GENERAL SUMMARY

POTENTIAL BENEFITS

LEVELS OF ASSURANCE

RELATIONSHIP TO THIRD PARTY EVALUATTONS

EFFECT ON COMPETTTION MAY HAVE BENEFITS AND DISADVANTAGES.

PROPOSED MODEL

CRITERIA BASE

POSSIBLE METHODOLOGIES AND APPROACHES

10

GENERAL ISSUES

11

RECOMMENDED ACTIONS

APPENDIX A

PAPERS RECEIVED FROM THE UNITED STATES

PAPERS RECEIVED FROM CANADA 
3

Developmental Assurance Workshop Proceedings

3 


\section{Executive Summary}

Ninety eight participants from the US, EC, Canada, and Japan representing government agencies, both defense and civil, private corporations, evaluators, users, and vendors of trusted products met to discuss the concept of developmental assurance.

Very few representatives from the vendor community participated in the workshop. This is an area of concern. It was suggested that a second workshop be held with only vendors in attendance.

The majority of the participants felt that the concept of developmental assurance was valid. However, the participants suggested a cautiously optomistic approach to the implementation of a developmental assurance scheme.

The participants thought developmental assurance is a promising concept but it is as yet unproven. A great deal of study is needed to validate the concept.

The participants recommended that all future developmental assurance work take place on the international level. The results of any developmental assurance scheme should be exchangeable, repeatable and provide reciprocity. It was recommended that an international working group for developmental assurance be established.

The developmental assurance concept must first be proven at the lower levels of trust. Developmental assurance may provide a level of assurance that approaches the current $\mathrm{C} 2 / \mathrm{E} 2$. If this is possible, developmental assurance may then be extended to the higher levels of trust.

Developmental assurance may not replace third party evaluations completely but may help to speed up the evaluation process. Developmental assurance in combination with third party evaluation may provide a useful level of assurance in a more reasonable period of time. 


\section{Introduction}

The International Invitational Workshop on Developmental Assurance was held June 16-17, 1994 at the Turf Valley Hotel and Country Club in Ellicott City, Maryland. The Workshop was sponsored by the National Institute of Standards and Technology (NIST), the National Security Agency (NSA), the Canadian Communications Security Establishment (CSE), and the European Commission (EC). Ninety eight participants representing government agencies, private corporations, evaluators, purchasers and vendors of trusted products took part.

\section{Formulation of the Developmental Assurance Concept}

In November 1993, a meeting of senior execuitves from NIST, NSA, CSE, and the EC was held at NIST. The senior executives discussed various alternatives to the third party evaluation scheme. Third party evaluations tend to be expensive and resource consuming. The senior executives agreed that some assurrance may be gained from reliance on the development process. If a vendor was to follow and document a particular development method, a level of assurance may be gained. That is not to say that the governments would require that a vendor follow a particular development process but that the process followed by a vendor be documented and repeatable. The vendor would demonstrate the security enhancing features of the process used during development. Therefore, a level of assurance could be gained from the development process itself.

The senior executives agreed that developmental assurance may provide an adequate level of assurance for some users, particularily those in the commercial and civil sectors. It was also agreed that while developmental assurance may approach a level of assurance close to C2/E2 that a great deal of research needs to be done.

\section{Call for Papers}

In January 1994 a call for papers was issued requesting thought on developmental assurance. Seventy-seven papers were recieved and the authors were invited to participate in the Developmental Assurnace Workshop.

The papers received covered a wide variety of topics including:

Approaches to Developmental Assurance

Operationsal perspectives

Commercial Products

Tactical Systems

The Information Highway

Security Engineering Capability Maturity Model 
Common Criteria

Relationship to Evaluation

Quality Assurance

Although the accepted papers are not published in these proceedings a list of the papers is in contained in Appendix $A$.

\section{Format of the Workshop}

The papers received were of an extremely diverse nature and reflected individual perspectives, environments and experiences. It was clear from the papers that there was a disparate understanding of the definition of developmental assurance. The workshop participants needed to clearly define their understanding of the developmental assurance concept. The workshop committe organized the workshop into areas for discussion. These areas included:

Metrics - How can developmental assurance be measured? How can we establish useful metrics that are meaningful to the security community in the civil, defense and private sectors?

Process - What process could be used to measure developmental assurance? Could SEI or the Security Engineering Capability Maturity Model be used? Are there other approaches which may be appropriate?

Tradeoffs - How does developmental assurance relate to other methods of gaining assurance such as evaluation?

Assurance based on "people" - Can some level of assurance be gained based on the people involved? Does developmental assurance mean "certifying" in some way the people that perform the devlopment OR does it mean "certifying" the development process itself OR some combination of the two. How does quality assurance play into developmental assurance? Does quality add to the security of a product or system in any meaningful way?

Low/High Assurance - Are the needs the same? At what current level of assurance (C2?, E2?) would developmental assurance be useful/meaningful? Is developmental assurance appropriate at the higher assurance levels? Could developmental assurance be a building block towards higher assurance level?

The attendees were randomly assigned to small working groups in which they discussed the above topics. 


\section{Conclusions \& Recommendations}

\section{General Summary}

In general, the majority of the workshop participants agreed that the concept of developmental assurance is valid and potentially valuable. Use of notions described in the developmental assurance concept could provide benefits to the overall evaluation process.

Developmental assurance must be further investigated at the international level. The Workshop participants were very concerned about individual countries moving ahead on this concept without harmonization. Several participants stated the need to work closely together as an international community.

\section{Potential Benefits}

The Workshop attendees noted several potential benefits from the use of a developmental assurance scheme. Evaluations of both products and systems would be possible under a developmental assurance scheme. Developmental assurance may result in major cost reductions for third party evaluations.

The workshop participants also believed that the use of developmental assurance may result in the acceleration of third party evaluations. If developmental assurance can help to provide the necessary documentation, this may in turn help to speed up the evaluation process conducted by a third party.

Developmental assurance may also be useful in cutting the cost and time required for the accreditation process. The outputs of developmental assurance may provide some very useful information to certifiers and accreditors.

By shifting some of the evaluation workload to organizations performing developmental assurance, evaluations may be completed in a more timely manner. Developmental assurance may also be very useful in causing improvements to re-evaluation, and maintenance of evaluation ratings.

It was suggested that the use of developmental assurance as a alternative to third party evaluations may reduce or eliminate misleading evaluation rating claims. Such claims as "designed to meet" and "C2-like" can be misleading and confusing the to consumer. 
A scheme which encompasses developmental assurance will broaden the availability of security expertise and practice. Evaluation expertise will be spread to other organizations outside the government agencies. This may help to foster a wider community of computer security professionals

Developmental assurance may also result in greater availability of low assurance evaluated products, and a consequent increase in awareness and demand. If more organizations have the expertise to perform evaluations then the number of evaluated products will increase.

\section{Levels of Assurance}

Precise bounds of applicability and achievable levels of developmental assurance need further investigation. Developmental assurance should be introduced with lower level goals and, if successful, migrate upwards to the higher levels of trust.

\section{Relationship to Third Party Evaluations}

The combination of developmental assurance products, and developmental assurance with third party evaluation products should be feasible, but requires further study. The effect on and relationship with liabilities and insurance requires study.

Effect on competition may have benefits and disadvantages.

The developmental assurance scheme must fit naturally into current commercial activity and operations, and align with (and anticipate) industry trends. Although third party evaluation by Commercial Licensened Evaluation Facilities (CLEFs) was seen as providing improved throughput, it was not seen as responding to general commercial needs for products

It was generally agreed that there would be continuing requirement for third party evaluation. Developmental assurance would not replace third party evaluations but serve as a portion of the evaluation process. Use of Developmental assurance could potentially reduce the length of time required for a third party evaluation. 


\section{Proposed Model}

The Workshop Participants envisioned a four tiered approach to operating a developmental assurance scheme.

First, an international body will set standards and oversee the operation of the national bodies.

Second, the national bodies will regulate the operation of licensing agents in their individual areas.

Third, the Europeans CLEFs could form the basis of a model for a licensing agent. The CLEFs under this model, would be authorized to approve, license and audit the Developmental assurance process of vendor and potentially system integrators.

Fourth, the vendors and integrators would develop and deliver products, components and systems that carry their evaluation marking or warranty. This might take the form of a multi-factor evaluation vector rather than a simple passed indicator.

Additionally a mechanism for appeals and interpretations would be developed. The appeal process could operate either under the national or international schemes. The process of interpretation of developmental assurance reqirements must take place at the international level in order to prevent conflicting interpretations.

\section{Criteria Base}

There was a great deal of discussion about the criteria to be used for developmental assurance. It was the common view that a criteria must be established, possibly through the Common Criteria.

There are many specific requirements for developmental assurance that may need to be handled in separate documentation. 


\title{
Possible Methodologies and Approaches
}

The developmental assurance workshop did not result in the establishment of a single developmental assurance methodolgy or approach. Rather it explored a number of valid methodologies and approaches. It was suggested by the workshop participants that a combination of these approaches into a new framework may result in a useful methodology. This combination of valid approaches, perhaps with the development of some new methods, could provide an extremely effective developmental assurance framework.

The framework for developmental assurance must cover all stages and aspects of the design, implementation and delivery processes.

There is a considerable legacy of relevant tools and methodologies exist which should provide a solid basis for developmental assurance. These include:

\author{
- $\quad$ Capability Maturity Models \\ - $\quad$ ISO 9000-3 \\ - $\quad$ Formal methods \\ - Informal methods (object oriented etc.).
}

Developmental assurance methods must support some form of metric to assess performance and quality improvement.

\section{General /ssues}

The participants expressed concern about a number of general developmental assurance issues. The level of committment from the government agencies was unclear. The roles the government agencies were to take in the development of a developmental assurance scheme was also unclear.

The participants were also concerned about the inital costs of implementing a developmental assurance scheme. Costs of required resources from both the government agencies and the vendors were discussed. Some participants felt that a developmental assurance scheme would place a heavy burden on the vendors. There was also some discussions about the demonstrable trustworthiness of the vendors. Some particpants felt that it would not be acceptable to simply rely on the word of the vendor and that a third party review of vendor claims would always be required. 
The level of detail required for both the scheme and the vendor documentation was discussed. A great deal of guidance documentation will be required.

Since there were very few vendors in attendance, the commitment to a developmental assurance scheme by the vendors was questioned. It was unclear whether or not the vendors would accept a developmental assurance scheme.

A lengthy discussion about legal liabilities and insurance coverage took place during the workshop.

\section{Recommended Actions}

The North American and European sponsors will reflect on the results of the workshop, and consider further action. It was suggested that an international working group be formed to further explore the developmental assurance concept.

A significant number of participants indicated that they would be able to provide further support for developing the ideas of the workshop.

The opinion of the vendors and system integrators not represented at the workshop should be actively sought by the sponsors, perhaps through an additional workshop. Success of a developmental assurance scheme will greatly depend on getting support from the major vendors and integrators. 


\section{Appendix A}

Papers Received from the United States

Some Reflection on Development Assurance

Susan Rose Childers

Computer Sciences Corporation

Hanover, Maryland

Establishing a Unified Framework for Expressing Developmental Assurance Requirements in the Information Technology Security Evaluation Common Criteria

Ron S. Ross, Terry Mayfield, Stephen R. Welke, and John M. Boone Institute for Defense Analyses

$1801 \mathrm{~N}$. Beauregard Street

Alexandria, VA 223311-1772

Specification for a Unified Standard: Integration of the Common Criteria with the ISO 9000-3 Standard

Ed Kusik

Rockwell Space Operations Company

600 Gemini MS\# R11A

Houston, TX 77058

Tel: $\quad 713.282 .2566$

Fax: 713.282.4575

eMail: egkusik@rsochou.rockwell.com

Donald L. Evans

Unisys Government Systems

600 Gemini MS\#

Houston, TX 77058

Tel: $\quad 713.282 .4050$

Fax: 713.282.4575

eMail: dlevans@rsochou.rockwell.com 
Summary Paper -- Product Assurance: An Operational Perspective

Ronald E. Helsley

Sr. Systems Engineer

AlliedSignal Technical Services Corporation

600 Gemini MS\# B81A-555

Houston, TX 77058

Tel: $\quad 713.282 .2504$

Fax: 713.282 .4575

rehelsle@rsochou.rockwell.com

Donald L. Evans

Unisys Government Systems

600 Gemini MS\#

Houston, TX 77058

Tel: $\quad 713.282 .4050$

Fax: 713.282 .4575

eMail: dlevans@rsochou.rockwell.com

The New Alliance: Gaining on Security Assurance

Rene Sanchez

Rockwell Space Operations Company

600 Gemini MS\# R11A

Houston, TX 77058

Tel: $\quad 713.282 .4589$

Fax: 713.282 .4575

eMail: r?sanche@rsochou.rockwell.com

Donald L. Evans

Unisys Government Systems

600 Gemini MS\#

Houston, TX 77058

Tel: $\quad 713.282 .4050$

Fax: 713.282 .4575

eMail: dlevans@rsochou.rockwell.com

Position Paper for the International Workshop on Developmental Assurance

Stan Kurzban

62 Pond View Lane

Chappaqua, New York 10514 
Quality Management Systems Support Trusted Software

Timothy R. Stacey

Science Applications International Corporation

600 Gemini MS\# C56B

Houston, TX 77058

Tel: $\quad 713.282 .4423$

Fax: 713.282 .4575

eMail: staceyt@orvb.saic.com

Developmental Assurance for Commercial Products

Steven B. Lipner

Trusted Information Systems, Inc.

Glenwood, MD

Application of Trusted Technology in the Development of Tactical Systems

Diane M. Bishop

Computer Sciences Corporation

1301 Virginia Drive, Fourth Floor

Ft. Washington, PA 19034

The International Information Highway: Its Impact on Security and The Assurance Question

Developmental Assurance: Its Nature, Need, and Means

Guy King

Computer Sciences Corporation 
Acceptance of the Secunity Engineering Capability Maturity Model

Captain Julie L. Connolly, USAF

INFOSEC Systems Engineering Office

National Security Agency

Fort Meade, MD 20755

Tel: (410) 684-7374

JLConnolly@dockmaster.ncsc.mil

An International Red Team for Information Technology Security

Wilson F. Engel, III, Ph.D.

Research Director

INRI

Position Paper on Developmental Assurance

Gary Kincaid

McDonnell Douglas Aerospace

8201 Greensboro Dr.

McLean, VA 22102

Tel: 703.883 .3935

Gary_Kincaid@MDAISS.MDC.COM

Trade-Offs in Establishing a Software Process Security Standard

Edward G. Amoroso and Howard M. Israel

Secure Systems Department, AT\&T Bell Laboratories

Whippany, New Jersey 07981 - USA

Te: (201)386-\{6398 4678\}

\{e.amoroso h.israel\}@att.com

Development Assurance versus Evaluation Assurance: What can really be gained?

Noelle McAuliffe

Trusted Information Systems, Inc.

Glenwood, MD 
An Organizational Approach to Developing Quality Assurance Methods for Gaining Security Assurance in t Electric Utility Industry

Art Maria

Puget Sound Power and Light Company

MS-OBC/07N P.O. Box 97034

Bellevue, Washington 98004

maria@puget.com

Technical and Policy Position on Developmental Assurance

Steven Szep

K-Systems, Inc.

P. O. Box 269

Lambertville, NJ 08530

Tel: $\quad 609.397 .3288$

Developmental Assurance and Software Quality Assurance, A Common Ground

Jennie Benson

Lockheed Austin Division

P.O. Box 17100

Austin, Texas $78748-7100$

Position Paper on Developmental Assurance for Security Products

Ranwa Hadda and Deborah Downs

Aerospace Corporation

P.O. Box 92957

Los Angeles, CA 90009-2957

Tel: $310336-5288$

Additional Considerations for Reducing the Dependency upon Evaluation Assurance through Development Assurance

Donald Schmidt

Datmedia Corp.

Nashua, $\mathrm{NH}$

Tel: $603886-1570$ 
Position Paper on the Use of Developmental Assurance to Replace Evaluation

Richard Allen, Anthony Datel

Oracle Corporation

500 Oracle Parkway

Box 659405

Redwood Shores, CA 94065

rallen@oracle.com

adatel.uk@oracle.com

Evaluating Systems Composed of Certified Elements

Penny Klein

DISAICISS

Tel: $703756-7918$

DoD Information Technology Security Certification and Accreditation Process

(DITSCAP)

Penny Klein

DISANCISS

Tel: $703756-7918$

Process Assurance

Lisa A. Gallagher

CSC Professional Services Group

1340 Ashton Road, Suite E

Hanover, MD 21076

Phone: (410) 859-2862

FAX: $(410) 859-2859$

An Assurance Taxonomy

Douglas J. Landoll, David R. Wichers, Carl A. Souba

landoll@arca.md.com, wichers@arca.md.com, souba@arca.md.com

Arca Systems, Inc.

10320 Little Patuxent Parkway, Suite 1005

Columbia, MD 21044 
Security Engineering Capability Maturity Model: A Method for Assessing Process Assurance

Karen M. Ferraiolo

Arca Systems, Inc.

8229 Boone Blvd., Suite 610

Vienna, VA 22182

Tel: $\quad 703.734 .5611$

eMail: ferraiolo@arca.va.com

Assurance is an N-Space (Where $N$ is Hopefully Small)

Jeffrey Williams, Joel Sachs, Douglas Landoll, Diann Carpenter

williams@arca.va.com, sachs@arca.md.com, landoll@arca.md.com, carpenter@arpa.md.com

Arca Sustems, Ind.

8229 Boone Blvd., Suite 610

Vienna, VA 22182

Tel: $\quad 703.734 .5611$

Linking Digital Signatures with Manual Signatures

Viktor E. Hampel, James P. Craft, and Robert D. Smith, Jr.

Systems Research and Applications Corporation

15th Street North

Arlington, BA 22201

Tel: 703.681 .0128

Fax: 703.681 .0165

Building Security and Quality into System Architectures

John Voltmer

The Solution Center

5723 Twin Brooks Drive

Dallas, Texas 75252

Tel: 214 447-0666

Position on Using Quality Assurance Methods to Gain Security Assurance

Sue LeGrand, MS, CISSP

72 Harbor Lane

Kemah, TX 77565 
Electronic Labeling of Digital Products (Proposal for an International Protection Standard for Digital Products)

Victor E. Hampel

Consultant and Senior Technical Advisor to the

Office of the Secretary of Defense (AT\&T/DATDC)

5109 Leesburg Pike, Suite 701

Tel: 703.681 .0128

Fax: 703.681 .0165

Position Paper Concerning the Identification and Development of the Requisite Processes and Methods for Developmental Assurance

Robert A. Tannert

Galaxy Computer Services, Inc.

for the Department of Energy

Supply and Demand Security

Marshall D. Abrams, Jay J. Kahn, Lester J. Fraim, and James G. Williams The MITRE Corporation

Contingency Plans -- Murphy was an Optimist

Jay J. Kahn, Marshall D. Abrams, Lester J. Fraim, and James G. Williams The MITRE Corporation

How Do You Decide How Much Assurance is Enough?

Marshall D. Abrams, Jay J. Kahn, Lester J. Fraim, and James G. Williams The MITRE Corporation

Developmental Assurance Benefits of the Capability Maturity Model

Craig A. Schiller

Science Applications International Corporation

600 Gemini MS\# C56B

Houston, TX 77058

Tel: $\quad 713.282 .6650$

Fax 713.282.4575

eMail: schillerc@orvb.saic.com 
The Need for 'Personal Assurance' of IT Security Specialists

Richard C. Koenig, Program Director International Information Systems Security Certification Consortium (ISC) ${ }^{2}$ Suite 1000, Park View Office Tower Worcester, MA 01609-1946, U.S.A Tel: 508.842 .0452 eMail: 72632.3207@compuserv.com

The ISSA-Sponsored Committee to Develop and Promulgate Generally accepted System Security Principles (GSSP)

Will Ozier

Ozier, Peterse, \& Associates

870 Market St., Suite 1001

San Francisco, CA 94102

Tel: $\quad 415.989 .9092$

Fax: $\quad 415.989 .9101$ 


\section{Papers Received from Canada}

Improving Security Through Vendor Participation -- A Position Paper

William Brierley and Richard Doucette

Brierley, Doucette \& Simpson Consulting Ltd.

1308 Wellington Street

Ottawa ON K1Y 3B2

Canada

eMail: wbrierley@bix.com, rdoucett@cse.dnd.ca

Position Paper for International Invitational Workshop on Developmental Assurance

Dan Craigen

ORA Canada

267 Richmond Road, Suite 100

Ottawa, Ontario K1Z6X3

Canada

eMail: dan@ora.on.ca

Tel: $+1613 / 722-3700$

Developmental Assurance and Risk Management

D. S. Crawford

D Secur Ops 4-3

Department of National Defence

Ottawa, Canada

Tel: $\quad$ (613) 945-7255

eMail: dcrawfor@cse.dnd.ca

The Role of ISO 9000 -- Quality Assurance in Providing Security Product Assurance

Terry Fletcher, B. Eng., M. Sc

AEPOS Technologies Corporation

601 - 116 Albert Street

Ottawa, Ontario

K1P 5 G3 
Developmental Assurance a Developmental Process

Kimberly Dwight Greenizan

INFOSEC Engineering

Computing Devices Canada

1020 - 68th Avenue N.E.

Calgary Alberta

T2E 8P2

Developmental Assurance in Product Evaluation

J. P. Hopkinson

Unification of Security Modeling Techniques

William Sandberg-Maitland

Senior Consultant

CGI Information Systems and Management Consultants Inc.

Ottawa, Ontario, Canada

Tel: (613) 234-2155

Fax: (613) 234-6934

eMail:wsandber@manitou.cse.dnd.ca

Position Paper for International Invitational Workshop on Developmental Assurance

Gary Maxwell

DOMUS Software Limited

1.Cooper Street, 5th Floor

Ottawa, Ontario, Canada

K2P OG5

Tel: $\quad$ (613) 230-6285

Fax: (613) 230-3274

The Use of Risk Assessment to Select an Appropriate Product Development Process

Tim Moses, Ph. D.

AEPOS Technologies Corporation

601 - 116 Albert St.,

Ottawa, Ontario

K1P $3 G 4$ 
Developmental Assurance Proposal

Andrew Robison

CSE, Canada

The Development of Functionality, Assurance, and Evaluation Complexity and Suggestions for Simplification

Wm. M. Steward, Ph. D.

Martin Marietta Canada

Ottawa, Ontario

Canada, K1P 6L2

StewartWM @aol.com

Julie Hass, B.S.E.E

Martin Marietta Astronautics

2025 Research Parkway

Colorado Springs, CO

U.S.A., 80920

Elton Ashby, M.S.

Martin Marietta Canada

Ottawa, Ontario

Canada, K1P 6L2

Trust through Assurance (Assurance Through Experience)

Paul Teeple

Officer in Charge

EDP Security Branch

Royal Canadian Mounted Police

Tel: (613) 993-8783

B1 Security Verification \& Validation: 3 DAYS VERSUS 3 YEARS

Peter P.C.H. Kingston, B.Sc, ISP, CISSP

The Kingston Group \& Associates Limited 
Papers Received from Europe

IBAG Contribution to International Invitational Workshop on Development Assurance

Chris Amery

INFOSEC Business Advisory Group (IBAG)/ZERGO LTD.

The Square

Basing View

UK-RG21 2EQ Basingstoke

Potential Contribution of Conformance Testing Methods to Security Evaluation

Roy Cadwallader,

Managing Director, ENACT Ltd., UK

International Invitational Workshop on Developmental Assurance -- Summary Paper

Senior Consultant Tor Olav Grotan, Senior consultant Kenneth R. Iversen, dr ing Norwegian Centre for Medical Informatics (KITH)

Medisinsk Teknisk Senter

7005 Trondheim, Norway

Tel: $\quad+4773598600$

Fax: +4773598611

email: tor.grotan@mtfs.unit.no

kenneth.iversen@mtfs.unit.no

No title

Subject: The BT System Security Evaluation and Certification Scheme

Peter Harding

Manager Electronic Security Projects

BT Commercial Security Unit

Emsworth ATE

Warblington Rd

EMSWORTH

Hants PO10 7HQ

United Kingdom

Tel: $\quad$ +44243370682

Fax: +44243370681 
Paper for Vendor Assurance Workshop: A Total Package on Information Security

Nigel Hickson

Management and Technology Division

Department of Trade and Industry

Developmental Assurance, the Need and a Possible Framework

Per Hoving,

Saab-Scania AB, Sweden

Security Evaluation in an OSI Context

Gary Jones

EDS

Pembroke House

Pembroke Broadway

Camberle

Surrey

GU15 4UF

UK

An Integrative Approach and a Proposal for a Metric

Dr. Heinrich Kersten

BSI - Bundesamt für Sicherheit in der Informationstechnik,

Bonn, Germany

Tuning Process Capability to Assure Required Security Levels

Lech Krzanik

Department of Informatin Processing Science

University of Oulu

Linnanmaa, FIN-90570 Oulu,

Finland

Tel: $\quad+358.815531922$

Fax: +358.815531890

eMail krzanik@rieska.oulu.fi 
Jouni Similä

CCC Software Professionals Oy

Lentokentäntie 15, FIN-90460 Oulunsalo

Finland

Tel: $\quad+358.81481122$

Fax: $\quad+358.81481168$

Position Paper on Developmental Assurance

Helmut Kurth

IABG

Einsteinstr. 20

D-85521 Ottobrunn

Germany

eMail kurth@ite.iabg.de

To Build an Affordable Software Engineering Environment for the Development of Secure Systems

Amuary LEGAIT

SYSECA

315, Bureaux de la Colline

92213 Saint Cloud Cedex

France

Tel: $\quad+33149117385$

Fax: +33149117645

eMail amaury@syseca.fr 
Security Quality through Security Engineering Methodology

Michèle Zurfluh-Vallant, Jean-Marc Lermuzeaux

Alactel Alsthom Recherche

Response to Call for Papers - International Invitational Workshop on Developmental Assurance

Wendy R. London

Senior Principal Consultant - CDG

Oracle Corporation UK

Statement of Position on Self Certification in ITSEC

Unknown author

PC Security Limited

The Old Court House

Trinity Road

Marlow, Bucks SL7 3AN

Tel: 0628890390

Fax: 0628890116

ISO 9000 -- Quality Standard Based Network Services Security Architecture

Mr. Juha E. Miettinen

Manager, Information Security

Telecom Finland

2. O. Box 106

FIN-00511 Helsinki

Finland

Tel: $\quad+358020403877$

Fax: +358020403887

eMail: Juha.Miettinen@qm.ajk.tele.fi

The Place of Developmental Assurance

Dr. R. Pizer

Head of Certification Body

UK ITSEC Scheme, PO Box 152

Cheltenham GL52 5UF

United Kingdom 
Summary Paper for International Workshop on Development Assurance

Richard Polis

Groupe de Management Genève

Geneva Management Group

Chemin du Lévrioux

Case Postale 23

$\mathrm{CH}-1263$ Crassier

Suisse

Tel: $\quad$ (022) 3671093

Fax: (022) 3671141

Télex: 419503

Practical Experience With Evaluation Assurance of Commercial Security Products

Bart PRENEEL

Katholieke Universiteit Leuven, Belgium and University of California at Berkeley

International Harmonization of Information Security Assessments

Folkert RIENSTRA (Chairman ITQS)

KEMA

P. O. Box 9035

6800 ET ARNHEM

The Netherlands

Tel: $\quad+3185566223$

Fax: +3185563205

eMail: f.rienstra(A)mta3.kema.nl

Security Evaluation, Quality Assurance and Conformance

Bronia Szczygiel

Data Security Group

NPL

Summary Paper for the Developmental Assurance Workshop

lan Uttridge

Logica Defence and Civil Government Ltd

68 Newman Street

London W1A 4SE UK

uttridgei@Lgsh.Logica.com 
International Invitational Workshop on Developmental Assurance - A Position Paper on Vendor Assurance

Unknown author

Admiral Management Services Limited

Kings Court

91-93 High Street

Camberley, Surrey GU15 3RN

Developmental Assurance, the Need and a Possible Framework

Per Hoving,

Saab-Scania AB, Sweden 

